\title{
Utilização de paclobutrazol em vetiver na produção de mudas e seu efeito em plantas no campo
}

\author{
Arie F Blank; José WA de Paula; Maria de Fátima Arrigoni-Blank; Maria A Moreira \\ UFS-Depto . Engenharia Agronômica, Av. Marechal Rondon s/n, 49100-000 São Cristóvão-SE; afblank@ufs.br; weltonze@hotmail.com; \\ arrigoni@ufs.br; hij47@hotmail.com
}

\section{RESUMO}

O efeito de paclobutrazol foi avaliado na produção de mudas de genótipos de vetiver (ensaio 1) e após transplantio em campo (ensaio 2) visando a redução da altura da planta e o aumento da produção de perfilhos. No ensaio 1 testaram-se dois genótipos de vetiver oriundos do Banco Ativo de Germoplasma da Universidade Federal de Sergipe, duas épocas de aplicação (7 e 14 dias após o plantio) e sete doses de paclobutrazol. No ensaio 2 foram avaliados três genótipos de vetiver e três modos de aplicação de paclobutrazol, sendo duas em mudas e uma em plantas em campo. Em mudas, a aplicação aos 14 dias após o plantio em tubetes, reduziu a altura de planta e a massa seca de parte aérea e de raiz. A maior concentração de paclobutrazol (1.800 $\mathrm{mg} \mathrm{L}^{-1}$ ) resultou em plantas mais baixas e menor massa seca de parte aérea. O paclobutrazol não influenciou o número de perfilhos por planta e não deve ser recomendado na produção de mudas de vetiver. Verificou-se que os genótipos UFS-VET001 e UFS-VET004 obtiveram maior perfilhamento por touceira a partir de 133 dias após transplantio para o campo; não houve diferenças significativas entre os genótipos para número de pendões florais por touceira, altura de planta, massa seca de parte aérea e de raiz e teor de óleo essencial. A aplicação de paclobutrazol proporcionou redução no número de pendões florais e altura de planta, mas não afetou a massa seca de parte aérea e de raízes. O paclobutrazol não deve ser recomendado para produção comercial de raízes de vetiver por não proporcionar redução de parte aérea e aumento do rendimento de raiz e de óleo essencial.

Palavras-chave: Chrysopogon zizanioides, planta medicinal e aromática, genótipo, regulador de crescimento, perfilhamento, óleo essencial.

\begin{abstract}
Utilization of paclobutrazol in vetiver for plantlet production and its effect over plants in the field

The effect of paclobutrazol was evaluated on plantlet production of different vetiver genotypes (assay 1) and on plants under field conditions (assay 2). In the first assay, two vetiver genotypes from the Germplasm Repository of Sergipe Federal University, Brazil (UFSVET001 and UFS-VET003), seven concentrations of paclobutrazol and two moments of application ( 7 and 14 days after planting) were evaluated. In the field assay, the treatments were three vetiver genotypes and three methods of application of paclobutrazol. Two product applications were performed at plantlet stage and one when plants were in the field. The application on 14-day old plants in the nursery reduced plant height and dry weight ofaerial part and roots. The highest paclobutrazol concentration $(1,800 \mathrm{mg} \mathrm{1-1)}$ resulted in shorter plants and lower dry weight of aerial part. Paclobutrazol did not influence the number of tillers per plant and should not be recommended for production of vetiver plantlets. In the field assay, the genotypes UFS-VET001 and UFS-VET004 had major tillering at 133 days after transplanting; there were no significant differences between the genotypes for the variables number of ears, plant height, dry weight of aerial part and roots, and essential oil content. The application of paclobutrazol proportioned reduction on the number of ears and plant height, but did not affect dry weight of aerial part and roots. Paclobutrazol should not be recommended for commercial production of vetiver roots because it did not reduce the aerial part and did not increase roots and essential oil yield as well.
\end{abstract}

Keywords: Chrysopogon zizanioides, medicinal and aromatic plant, genotype, growth regulator, tillering, essential oil.

(Recebido para publicação em 21 de dezembro de 2007; aceito em 2 de julho de 2009) (Received in December 21, 2007; accepted in July 2, 2009)

$\mathrm{O}$ vetiver [Chrysopogon zizanioides (L.) Roberty syn. Vetiveria zizanioides (L.) Nash] (Poaceae) é uma espécie medicinal e aromática originária da Ásia Tropical (Índia, Ceilão e Malásia) e popularmente conhecida por capim-cheiroso, falso-patchouli, capimbarata, khus-khus ou khas-khas (Índia) (Castro \& Ramos, 2002; Adams et al., 2003). De acordo com Adams \& Dafforn (1999) o vetiver pode ser subdividido em dois grandes grupos, com e sem óleo essencial.

Em geral o grupo com óleo essencial é infértil ou apresenta baixo nível de fertilidade. Existe variabilidade genética, dentro do grupo com óleo essencial, para as variáveis, teor e rendimento de óleo essencial e teores de compostos químicos presentes no óleo essencial (Adams et al., 2003).

Segundo Lavania (2000), o Centro de Origem Primária de vetiver, de acordo com estudos morfotaxonômicos desta espécie, é o Sul da Índia, de onde se espalhou para o mundo. Nesta mesma região foi encontrada a maior diversidade para as variáveis reprodução sexuada, encontrando desde indivíduos estéreis até alguns que produzem poucas sementes, e composição química do óleo essencial, encontrando indivíduos com constituintes químicos distintos no óleo essencial, o que levou o autor a sugerir o sul da Índia como Centro de Origem. 
O vetiver é uma espécie perene, com caule rizomatoso, cilíndrico e raízes aromáticas. As folhas são alternas dísticas, relativamente rígidas, compridas (até $75 \mathrm{~cm}$ ), finas (menos de $8 \mathrm{~mm}$ ) e lisas. As inflorescências são do tipo panícula (15 a $30 \mathrm{~cm}$ de comprimento), espiguetas sésseis com duas flores, sendo a superior hermafrodita (com três estames, anteras rimosas, dois estigmas plumosos e ovário súpero) e a inferior masculina (Veldkamp, 1999; Souza \& Lorenzi, 2005).

$\mathrm{O}$ vetiver possui perfilhação abundante e por isso é usado na formação de barreiras para contenção do solo em áreas inclinadas. Sua parte aérea (colmos e folhas) é usada para a cobertura de construções rurais rústicas, para o artesanato (esteiras, biombos, divisórias, etc.) e para a cobertura do solo (Adams et al., 2004).

As raízes são usadas, ao natural, como repelentes de insetos para uso doméstico (Castro \& Ramos, 2002). O óleo essencial extraído do vetiver apresenta forte atividade cupinicida, antimicrobiana e antioxidante (Kim et al., 2005). Segundo Alencar et al. (2005), essa planta possui efeito anti-hipertensivo leve e também efeito diurético, sendo utilizada ainda no tratamento de queda de cabelos.

As raízes, depois de secas e cortadas, podem ser utilizadas para extração de um óleo essencial espesso cor de âmbar, constituído principalmente por vetivona (Adams et al., 2003).

O óleo essencial de vetiver é composto, principalmente, por sesquiterpenóides, possui aroma que varia do doce à terra e madeira, sendo muito apreciado pela indústria de perfumes, onde é utilizado como fixador (Martinez et al., 2004). Também é usado na aromaterapia e em alimentos, como aromatizante em conservas de aspargos e ervilhas e como flavorizante em algumas bebidas (Martinez et al., 2004).

Os retardantes de crescimento são muito estudados. Estes são utilizados em diferentes áreas como por exemplo, na redução dos efeitos negativos provocados por estresses ambientais, induzindo mudanças no metabolismo da planta, o qual aumenta a resistência em condições desfavoráveis (Özmen et al., 2003), além de serem amplamente usados em plantas mantidas em vasos (Barrett, 1992).

Os reguladores de crescimento têm apresentado grande potencial de utilização na agricultura em função de seus efeitos sobre diferentes processos fisiológicos das plantas (Resende \& Souza, 2002). Dentre os mais comuns pode-se citar o paclobutrazol (Bonzi ${ }^{\circledR}$ ), o daminozide (B-nine ${ }^{\circledR}$ ) e o cloreto de chlormequat $\left(\mathrm{Cycocel}^{\circledR}\right)$.

O paclobutrazol possui maior atividade residual no substrato, sendo efetivo em concentrações baixas e aplicação única, além de ser mais eficiente quando aplicado ao substrato comparado à aplicação foliar, pois é translocado quase que exclusivamente pelo xilema e pouco pelo floema.

$\mathrm{Na}$ aplicação foliar, o produto deve se mover através do floema para atingir o xilema e ser translocado aos meristemas de crescimento. $\mathrm{Na}$ aplicação via substrato é absorvido pelas raízes e translocado diretamente para os pontos de crescimento pelo xilema (Barrett, 1992).

O paclobutrazol tem sido muito utilizado para evitar o tombamento de plantas de cereais, devido ao seu efeito inibidor no alongamento dos entrenós reduzindo, assim, o porte da planta (Berova \& Zlatev, 2003). Em vetiver, a aplicação do paclobutrazol proporcionou aumento de $52 \%$ no número de inflorescências, além de antecipar a floração em 14 dias, enquanto que o daminozide $\left(4 \mathrm{~g} \mathrm{~L}^{-1}\right)$ proporcionou maior perfilhamento aos 30 dias após aplicação em plantas com 60 dias (Xia, 2004).

Na micropropagação de vetiver são usados segmentos nodais obtidos de hastes florais como explantes (Almeida et al., 2007). Assim, o perfilhamento e a produção de maior número de hastes florais são essenciais para viabilizar a produção de mudas através da cultura de tecidos.

O presente trabalho teve como objetivo avaliar o efeito de paclobutrazol (PBZ) na produção de mudas de genótipos de vetiver (ensaio 1) e após transplantio para o campo (ensaio 2) com relação ao crescimento em altura e número de perfilhos por touceira.

\section{MATERIAL E MÉTODOS}

Os ensaios foram implantados em campo da UFS, situado no município de São Cristóvão, latitude $11^{\circ} 00^{\prime} \mathrm{S}$, longitude $37^{\circ} 12^{\prime} \mathrm{W}$ e altitude de $47 \mathrm{~m}$, de 11 de agosto de 2006 a 08 de setembro de 2006 (ensaio 1) e de 28 de novembro de 2006 a 20 de junho de 2007 (ensaio 2).

As mudas de vetiver foram obtidas de matrizes do Banco Ativo de Germoplasma da UFS. As touceiras foram separadas em perfilhos os quais foram padronizados com $20 \mathrm{~cm}$ de parte aérea e cortados em bisel. As raízes foram cortadas e logo depois as mudas foram plantadas em tubetes de $110 \mathrm{~cm}^{3}$.

Como substrato utilizou-se pó de coco lavado, e em cada litro deste substrato acrescentou-se $1 \mathrm{~g}$ de calcário dolomítico e $6 \mathrm{~g}$ do fertilizante NPK 6-24-12 + micronutrientes ( $\mathrm{Ca}, \mathrm{S}, \mathrm{Zn}, \mathrm{B}$, $\mathrm{Cu}, \mathrm{Fe}, \mathrm{Mn}$ e B a 6, 0-5, 0-0, 2-0, 05-0,02$0,15-0,10$ e $0,003 \%$, respectivamente). As mudas foram mantidas em ambiente protegido com tela branca de malha $30 \%$ e irrigadas diariamente por microaspersão por dez minutos.

Influência de paclobutrazol na fase de produção de mudas (ensaio 1) - Foi utilizado o delineamento experimental de blocos casualizados, em esquema fatorial $2 \times 2 \times 7 \mathrm{e}$ os tratamentos foram dois genótipos (UFS-VET001 e UFS-VET003), duas épocas de aplicação (7 e 14 dias após plantio) e sete doses de PBZ (0, 300, 600, 900, 1200, 1500 e $\left.1800 \mathrm{mg} \mathrm{L}^{-1}\right)$ na quantidade de $2 \mathrm{~mL}$ por planta, aplicado com seringa diretamente no substrato nos tubetes. Foram utilizadas três repetições sendo cada parcela constituída por quatro tubetes de $110 \mathrm{~cm}^{3}$ de capacidade com uma muda por tubete.

Aos 28 dias após a implantação do ensaio avaliou-se a sobrevivência (\%) pela contagem das mudas vivas de cada parcela, transformado em porcentagem; número de perfilhos por planta com a quantificação do número de perfilhos de cada muda da parcela dividido pelo número total de mudas vivas; altura de planta $(\mathrm{cm})$ pela medida da altura das mudas vivas de cada parcela com fita 
métrica e utilizando-se a média para representar a parcela; massa seca de folhas e de raízes por planta $(\mathrm{g})$, com corte das folhas e raízes das mudas vivas de cada parcela, secagem em estufa com fluxo de ar forçado, à temperatura de $80^{\circ} \mathrm{C}$ até massa constante e peso em balança semi-analítica, sendo a média representativa da parcela.

Os dados foram submetidos à análise de variância e as médias de genótipos e de épocas de aplicação de PBZ foram comparadas pelo teste de $\mathrm{F}(\mathrm{p} \leq 5 \%)$. Foi aplicada a regressão polinomial para avaliar o efeito das doses de PBZ estudadas.

Influência de paclobutrazol em plantas após transplantio em campo (ensaio 2) - Mudas com 25 dias de idade, contados a partir do dia de plantio, foram transferidas para o campo para implantação do ensaio. $\mathrm{O}$ delineamento experimental foi de blocos casualizados, em esquema fatorial $3 \times 3$, sendo três genótipos de vetiver (UFS-VET001, UFS-VET003 e UFS-VET004) e três tratamentos com PBZ $[0 ; 1.500 \mathrm{mg}$ $\mathrm{L}^{-1}$ aplicado aos 15 dias após o plantio (tubetes); $1.500 \mathrm{mg} \mathrm{L}^{-1}$ aplicado aos 15 dias após o plantio (tubetes) e aos 30 dias (campo)].

Foram feitas aplicações de $2 \mathrm{~mL}$ de PBZ por tubete e $5 \mathrm{~mL}$ por planta em campo, aplicando-se com seringa diretamente no substrato dentro cada tubete ou no solo junto ao colo de cada planta em campo.

O ensaio constou de três repetições e cada parcela foi constituída por quatro linhas com quatro plantas cada, sendo que a parcela útil foi composta pelas quatro plantas centrais.

O espaçamento utilizado foi $1 \mathrm{~m}$ entre linhas e entre plantas. Para o preparo do solo foi realizada calagem aplicando-se $2 \mathrm{t} \mathrm{ha}^{-1}$ de calcário dolomítico, de acordo com análise do solo. A adubação de fundação consistiu do uso de $10.000 \mathrm{~L} \mathrm{ha}^{-1}$ de esterco bovino; $500 \mathrm{~kg} \mathrm{ha}^{-1}$ de NPK 6-24-12 + micronutrientes $(\mathrm{Ca}, \mathrm{S}, \mathrm{Zn}, \mathrm{B}, \mathrm{Cu}, \mathrm{Fe}, \mathrm{Mn}$ e B a 6,0-5,0-0,2-0,05-0,02-0,15-0,10 e $0,003 \%$, respectivamente). Aos 90 dias após o transplantio das mudas realizouse adubação de cobertura com $500 \mathrm{~kg}$ ha $^{-1}$ de NPK 6-24-12 + micronutrientes
(Ca, S, Zn, B, Cu, Fe, Mn e B a 6,05,0-0,2-0,05-0,02-0,15-0,10 e 0,003\%, respectivamente). A irrigação foi realizada por gotejamento, sempre nos dias com ausência de chuvas.

As variáveis avaliadas foram: perfilhos por touceira pela contagem do número de perfilhos, semanalmente, durante 26 semanas, sendo a média utilizada para representar a parcela; pendões florais por touceira pela contagem do número de pendões florais aos 182 dias após transplantio e calculada a média por parcela; altura de planta $(\mathrm{cm}) \mathrm{me}$ dida a partir da inserção da touceira no solo até a ponta da folha mais alta, com o auxílio de fita métrica, calculando-se a média por parcela; massa seca de folhas por planta $\left(\right.$ g planta $\left.^{-1}\right)$, com corte de folhas de cada parcela, secagem em estufa com fluxo de ar forçado, à temperatura de $80^{\circ} \mathrm{C}$ até massa constante, pesagem em balança semi-analítica, e calculada a média por parcela; massa seca de raízes $\left(\right.$ g planta $\left.^{-1}\right)$, pelo arranquio de touceiras do solo com o auxilio de enxadeco, cavando-se um buraco com 0,30 $\mathrm{m}$ de raio e profundidade de $0,40 \mathrm{~m}$, corte e secagem de raízes, em estufa com fluxo de ar forçado à temperatura de $40^{\circ} \mathrm{C}$ por cinco dias e pesagem em balança semianalítica; teor (\%) de óleo essencial, obtido através da hidrodestilação, em aparelho do tipo Clevenger, de raízes secas $(100 \mathrm{~g})$ em balão de fundo redondo de 3,0 L de capacidade.

Os dados foram submetidos à análise de variância e as médias foram comparadas pelo teste de Tukey $(\mathrm{p} \leq 5 \%)$.

\section{RESULTADOS E DISCUSSÃO}

Influência de paclobutrazol na fase de produção de mudas - Não foram observadas interações significativas entre os fatores testados (genótipos x épocas de aplicação, genótipos x doses de PBZ, épocas de aplicação $\mathrm{x}$ doses de PBZ, genótipos $\mathrm{x}$ épocas de aplicação $\mathrm{x}$ doses de PBZ). Na produção de mudas em tubetes, os dois genótipos de vetiver avaliados, UFS-VET001 e UFS-VET003, não apresentaram diferenças significativas para as variáveis sobrevivência de mudas, altura de planta, número de perfilhos por touceira e massa seca de parte aérea. Entretanto, maior acúmulo de massa seca de raiz foi observado para o genótipo UFS-VET001 (Tabela 1). Em relação às épocas de aplicação de $\mathrm{PBZ}$, houve diferença significativa para altura de planta e massa seca de parte aérea e de raiz (Tabela 1 ).

Aos sete dias após o plantio nos tubetes, provavelmente, não houve produção de raízes suficientes para permitir a absorção de PBZ, não sendo observado, assim nenhum efeito de redução na altura das plantas e massa seca de parte aérea e raiz. A aplicação de PBZ realizada aos 14 dias após o plantio (DAP) proporcionou a obtenção de mudas menores e com menor produção de massa seca de parte aérea e de raiz quando comparado ao tratamento de aplicação de PBZ realizada aos 7 dias.

Não houve diferença significativa entre as doses de PBZ avaliadas para sobrevivência de plantas, número de perfilhos e massa seca de raiz, apresentando médias de 93,45\%, 1,47 perfilhos e $0,06 \mathrm{~g}$, respectivamente. Resultados diferentes foram obtidos por Xia (2004), para genótipos de vetiver nativos da China, onde a aplicação de 1,2 $\mathrm{g} \mathrm{L}^{-1}$ de PBZ aos dois meses após o plantio em campo, proporcionou o aumento no número de perfilhos.

Respostas diferenciadas entre genótipos, além de outros fatores tais como condições de condução do experimento, manejo da cultura, nutrição e condições ambientais, poderiam explicar a aparente discordância entre os resultados aqui produzidos e aqueles obtidos por Xia (1994).

Com relação à altura de planta, esta é representada por uma equação linear, sendo que a dose de $1.800 \mathrm{mg} \mathrm{L}^{-1}$ proporcionou menor altura, comprovando seu efeito como redutor de crescimento (Berova \& Zlatev, 2003). A massa seca de parte aérea apresentou resposta cúbica em função da dose de PBZ estudada (Tabela 1). Observou-se que, de zero até $600 \mathrm{mg} \mathrm{L}^{-1}$ de PBZ por planta houve redução na produção de massa seca de parte aérea de 0,281 para 0,168 g planta $^{-1}$; de 600 a $1.410 \mathrm{mg} \mathrm{L}^{-1}$ a resposta foi estável, com produção de até $0,185 \mathrm{~g}$ de massa seca de parte aérea por planta ${ }^{-1}$, e na dose de $1.410 \mathrm{mg} \mathrm{L}^{-1}$ a $1.800 \mathrm{mg} \mathrm{L}^{-1}$ 
Tabela 1. Altura de planta e massa seca da parte aérea e de raiz de vetiver, após 28 dias de plantio em tubetes, em função de genótipos, época de aplicação e concentração de paclobutrazol (plant height and dry weight of aerial part and roots of vetiver, 28 days after planting in tublets, as a function of genotypes, time of applications and paclobutrazol concentration). São Cristóvão, UFS, 2007.

\begin{tabular}{|c|c|c|c|}
\hline \multirow{2}{*}{ Genótipo } & \multirow{2}{*}{$\begin{array}{l}\text { Altura de planta } \\
\qquad(\mathrm{cm})\end{array}$} & \multicolumn{2}{|l|}{ Massa seca (g) } \\
\hline & & Parte aérea & Raiz \\
\hline UFS-VET001 & $39,58 \mathrm{a}^{1}$ & $0,19 \mathrm{a}$ & $0,07 \mathrm{a}$ \\
\hline UFS-VET003 & $36,63 \mathrm{a}$ & $0,18 \mathrm{a}$ & $0,05 \mathrm{~b}$ \\
\hline \multicolumn{4}{|l|}{ Época de aplicação } \\
\hline 7 dap $^{2}$ nos tubetes & $40,30 \mathrm{a}$ & $0,21 \mathrm{a}$ & $0,07 \mathrm{a}$ \\
\hline 14 dap nos tubetes & $35,90 \mathrm{~b}$ & $0,16 \mathrm{~b}$ & $0,05 \mathrm{~b}$ \\
\hline \multicolumn{4}{|c|}{ Paclobutrazol $\left(\mathrm{mg} \mathrm{L}^{-1}\right)$} \\
\hline Controle & 46,96 & 0,28 & 0,07 \\
\hline 300 & 40,83 & 0,20 & 0,07 \\
\hline 600 & 37,45 & 0,17 & 0,05 \\
\hline 900 & 34,46 & 0,16 & 0,05 \\
\hline 1200 & 38,02 & 0,19 & 0,07 \\
\hline 1500 & 34,72 & 0,17 & 0,05 \\
\hline 1800 & 34,29 & 0,16 & 0,06 \\
\hline Equação $(\hat{y}=)$ & $\begin{array}{l}43,33-0,006 \mathrm{x} \\
\mathrm{R}^{2}=0,70 * *\end{array}$ & $\begin{array}{l}0,281-3,81 \cdot 10^{-4} \mathrm{x}+3,95 \cdot 10^{-7} \mathrm{x}^{2}-1,23 \cdot 10^{-10} \mathrm{x}^{3} \\
\mathrm{R}^{2}=0,96^{* *}\end{array}$ & n.s. \\
\hline CV (\%) & 18,75 & 35,48 & 47,88 \\
\hline
\end{tabular}

${ }^{1}$ Médias seguidas de mesma letra nas colunas não diferem entre si pelo teste de $\mathrm{F}(\mathrm{p} \leq 0,05)$ (means followed by same letters in columns did not differ from each other by the $\mathrm{F}$ test $(\mathrm{p}<0,05)) ;{ }^{2}$ dias após o plantio (days after planting); ** significativa a $1 \%$ pelo teste de $\mathrm{t}(* *$ significant at $1 \%$ by the t test); n.s.: não significativo; (n.s.: not significant).

de PBZ houve redução de massa seca para 0,159 g planta $^{-1}$ (Tabela 1).

A resposta linear negativa proporcionada pelo aumento da dose de PBZ para altura de planta não foi observada para massa seca de parte aérea, provavelmente por ter provocado um maior crescimento em largura das folhas. Estudos realizados por Yim et al. (1997) revelaram que uma solução de $\operatorname{PBZ}(4,8$ X $\left.10^{-5} \mathrm{M}\right)$, pulverizada uniformemente no solo antes da semeadura de arroz, resultou, a partir da terceira folha, no maior crescimento em largura das folhas.

Dhaliwal et al. (1997a,b) observaram que a permanência de raízes de mudas micropropagadas durante $1 \mathrm{~h}$ em solução de $20 \mu \mathrm{g}$ de $\mathrm{PBZ}$ por $\mathrm{mL}$, resultou em redução da área foliar e número de estômatos em mudas de cana de açúcar micropropagadas e no aumento da massa seca de raiz.

Influência de paclobutrazol em plantas após transplantio em campo - O número de perfilhos por planta de 7 a 182 DAT em função dos genótipos e das aplicações de $1.500 \mathrm{mg} \mathrm{L}^{-1}$ de PBZ encontra-se ilustrado na Tabela 2.

O genótipo UFS-VET004 proporcionou maior perfilhamento por planta de 7 aos 119 DAT (Tabela 2). A partir desse período não houve diferenças significativas entre os genótipos UFS-VET001 e UFS-VET004, que mostraram-se superiores ao genótipo UFS-VET003. Respostas diferenciadas de genótipos de milho também foram observadas por Ali et al. (1998), à aplicação de 3.200 $\mathrm{mL}$ de PBZ por hectare aos 42 dias após semeadura.

As aplicações de PBZ não resultaram em aumento do perfilhamento aos 182 DAT, diferente dos resultados obtidos por Xia (2004) que observou aumento do perfilhamento quando aplicou $1.200 \mathrm{mg} \mathrm{L}^{-1}$ do produto em touceiras de um clone de vetiver chinês. Neste trabalho, aos 182 DAT, não foram observadas diferenças significativas entre os três genótipos de vetiver estudados (UFS-VET001, UFS-VET003 e UFSVET004), com relação ao número de pendões florais por touceira (média de 1,79 ), altura de planta (média de 149,7 $\mathrm{cm}$ ), massa seca de parte aérea (média de $316,79 \mathrm{~g}$ ) e de raiz (média de 82,53 g) e teor de óleo essencial (média de $0,95 \%$ ).

A ausência deste regulador de crescimento favoreceu a produção do maior número de pendões florais e altura de planta (Tabela 3). Esses resultados contradizem aqueles obtidos com o clone de vetiver chinês no qual o uso de PBZ aumentou em 52\% o número de inflorescências (Xia, 2004).

Atualmente, a produção comercial de mudas de vetiver é feita arrancandose plantas adultas no campo, separando os perfilhos e fazendo a toalete para posterior plantio em tubete.

Com o aumento de perfilhos por planta o número de plantas a serem arrancadas no campo para a produção de mudas será menor e consequentemente, mais plantas poderão ser colhidas para extração de óleo essencial a partir de raízes.

Na produção de mudas em tubetes, os genótipos UFS-VET001 e UFSVET003 não apresentaram diferenças significativas para sobrevivência, altura de planta, número de perfilhos por tou- 
Tabela 2. Número de perfilhos por touceira de vetiver dos 7 aos 182 dias após transplantio em campo, em função de genótipos e de aplicações com paclobutrazol (number of tillers per vetiver plant from 7 to 182 days after planting in field, as a function of genotypes and paclobutrazol applications). São Cristóvão, UFS, 2007.

\begin{tabular}{|c|c|c|c|c|c|c|c|c|c|}
\hline \multirow{2}{*}{ Genótipo } & \multicolumn{9}{|c|}{ Dias após transplantio em campo } \\
\hline & 07 & 14 & 21 & 28 & 35 & 42 & 49 & 56 & 63 \\
\hline $\begin{array}{l}\text { UFS-VET001 } \\
\end{array}$ & $1,22 \mathrm{~b}^{1}$ & $1,77 \mathrm{~b}$ & $2,69 \mathrm{~b}$ & $4,80 \mathrm{~b}$ & $6,91 \mathrm{~b}$ & 8,7 & $10,57 \mathrm{~b}$ & b $12,43 \mathrm{~b}$ & $15,01 \mathrm{~b}$ \\
\hline UFS-VET003 & $1,02 \mathrm{~b}$ & $1,36 \mathrm{~b}$ & $2,05 \mathrm{~b}$ & $3,00 \mathrm{c}$ & $4,05 \mathrm{c}$ & 6,0 & $7,49 \mathrm{c}$ & $9,02 \mathrm{c}$ & $10,75 \mathrm{c}$ \\
\hline UFS-VET004 & $1,55 \mathrm{a}$ & $2,36 \mathrm{a}$ & $3,50 \mathrm{a}$ & $6,38 \mathrm{a}$ & $9,36 \mathrm{a}$ & 12,3 & $14,80 \mathrm{a}$ & a $17,13 \mathrm{a}$ & $20,63 \mathrm{a}$ \\
\hline \multicolumn{10}{|l|}{ Paclobutrazol (1500 $\left.\mathrm{mg} \mathrm{L}^{-1}\right)$} \\
\hline Controle & $1,11 \mathrm{~b}$ & $1,58 \mathrm{~b}$ & $2,44 \mathrm{~b}$ & $4,36 \mathrm{~b}$ & $6,33 \mathrm{al}$ & 8,80 & $\begin{array}{c}11,05 \\
\mathrm{ab}\end{array}$ & $13,11 \mathrm{ab}$ & $16,00 \mathrm{a}$ \\
\hline 15 dap* (tubetes) & $1,16 \mathrm{~b}$ & $1,61 \mathrm{~b}$ & $2,52 \mathrm{~b}$ & $4,19 \mathrm{~b}$ & $5,86 \mathrm{~b}$ & 7,78 & $9,53 \mathrm{~b}$ & b $11,25 \mathrm{~b}$ & $13,62 \mathrm{a}$ \\
\hline $\begin{array}{l}15 \text { dap (tubetes) e } 30 \text { dat** } \\
\text { (campo) }\end{array}$ & $1,52 \mathrm{a}$ & $2,30 \mathrm{a}$ & $3,27 \mathrm{a}$ & $5,63 \mathrm{a}$ & $8,13 \mathrm{a}$ & 10,5 & $12,27 \mathrm{a}$ & a 14,23 a & $16,79 \mathrm{a}$ \\
\hline CV (\%) & 18,53 & 22,78 & 19,43 & 21,59 & 22,77 & 19 & 17,81 & 17,22 & 17,75 \\
\hline \multirow{2}{*}{ Genótipo } & \multicolumn{9}{|c|}{ Dias após transplantio em campo } \\
\hline & 70 & 77 & 84 & 91 & 98 & 105 & 112 & 119 & 126 \\
\hline UFS-VET001 & $18,50 \mathrm{~b}$ & $22,04 \mathrm{~b}$ & $25,83 \mathrm{~b} \quad 2$ & $27,27 \mathrm{~b}$ & $28,75 \mathrm{~b}$ & $33,24 \mathrm{~b}$ & $35,64 \mathrm{~b}$ & $38,09 \mathrm{~b}$ & $50,03 \mathrm{a}$ \\
\hline UFS-VET003 & $13,00 \mathrm{c}$ & $15,63 \mathrm{c}$ & $18,46 \mathrm{c} \quad 1$ & $19,70 \mathrm{c}$ & $21,24 \mathrm{~b}$ & $23,93 \mathrm{c}$ & $25,11 \mathrm{c}$ & $27,75 \mathrm{c}$ & $35,97 \mathrm{~b}$ \\
\hline UFS-VET004 & $25,13 \mathrm{a}$ & $29,61 \mathrm{a}$ & 34,47 a 3 & $36,13 \mathrm{a}$ & $38,13 \mathrm{a}$ & $43,58 \mathrm{a}$ & $46,02 \mathrm{a}$ & $48,88 \mathrm{a}$ & $57,47 \mathrm{a}$ \\
\hline \multicolumn{10}{|l|}{ Paclobutrazol (1500 $\left.\mathrm{mg} \mathrm{L}^{-1}\right)$} \\
\hline Controle & $19,33 \mathrm{a}$ & $23,36 \mathrm{a}$ & $27,22 \mathrm{a} \quad 2$ & $28,75 \mathrm{a}$ & $30,41 \mathrm{a}$ & $34,50 \mathrm{a}$ & $36,11 \mathrm{a}$ & $38,00 \mathrm{a}$ & $48,27 \mathrm{a}$ \\
\hline 15 dap* (tubetes) & $16,95 \mathrm{a}$ & $20,10 \mathrm{a}$ & 23,80 a 2 & $24,79 \mathrm{a}$ & $26,21 \mathrm{a}$ & $29,51 \mathrm{a}$ & $31,80 \mathrm{a}$ & $35,28 \mathrm{a}$ & $45,23 \mathrm{a}$ \\
\hline $\begin{array}{l}15 \text { dap (tubetes) e } 30 \text { dat** } \\
\text { (campo) }\end{array}$ & 20,36 a & $23,83 \mathrm{a}$ & 27,74 a 2 & $29,57 \mathrm{a}$ & $31,50 \mathrm{a}$ & $36,74 \mathrm{a}$ & 38,87 a & 41,44 a & $49,97 \mathrm{a}$ \\
\hline $\mathrm{CV}(\%)$ & 17,84 & 19,17 & 20,03 & 20,63 & 21,07 & 20,15 & 19,51 & 17,89 & 15,14 \\
\hline \multirow{2}{*}{ Genótipo } & \multicolumn{9}{|c|}{ Dias após transplantio em campo } \\
\hline & 133 & 140 & 147 & $\overline{15}$ & 54 & 161 & 168 & 175 & 182 \\
\hline$\overline{\text { UFS-VET001 }}$ & $61,54 \mathrm{a}$ & $68,32 \mathrm{a}$ & $77,16 \mathrm{a}$ & 83,0 & $03 \mathrm{a}$ & $87,94 \mathrm{a}$ & $92,75 \mathrm{a}$ & $98,59 \mathrm{a}$ & $104,49 \mathrm{a}$ \\
\hline UFS-VET003 & $43,87 \mathrm{~b}$ & $49,48 \mathrm{~b}$ & $55,91 \mathrm{~b}$ & 59,9 & $95 \mathrm{~b}$ & $63,46 \mathrm{~b}$ & $66,28 \mathrm{~b}$ & $70,38 \mathrm{~b}$ & $74,48 \mathrm{~b}$ \\
\hline UFS-VET004 & $67,02 \mathrm{a}$ & $72,50 \mathrm{a}$ & $81,75 \mathrm{a}$ & 87,0 & $00 \mathrm{a}$ & $91,72 \mathrm{a}$ & $96,00 \mathrm{a}$ & $102,88 \mathrm{a}$ & $108,88 \mathrm{a}$ \\
\hline \multicolumn{10}{|l|}{ Paclobutrazol (1500 $\left.\mathrm{mg} \mathrm{L}^{-1}\right)$} \\
\hline Controle & $58,25 \mathrm{a}$ & $63,88 \mathrm{a}$ & $73,00 \mathrm{a}$ & 77,8 & $83 \mathrm{a}$ & $82,47 \mathrm{a}$ & $86,88 \mathrm{a}$ & $91,27 \mathrm{a}$ & $96,11 \mathrm{a}$ \\
\hline \multirow{2}{*}{$\begin{array}{l}15 \text { dap* (tubetes) } \\
15 \text { dap (tubetes) e } 30 \text { dat** } \\
\text { (campo) }\end{array}$} & $55,26 \mathrm{a}$ & $61,61 \mathrm{a}$ & $69,76 \mathrm{a}$ & 75,1 & $12 \mathrm{a}$ & 79,19 a & $82,82 \mathrm{a}$ & $88,44 \mathrm{a}$ & $93,34 \mathrm{a}$ \\
\hline & 58 , & 6 & 72 & a & $03 \mathrm{a}$ & 81 & $32 \mathrm{a}$ & 9 & 98 \\
\hline $\mathrm{CV}(\%)$ & 14,73 & 14,92 & 14,96 & 14, & 95 & 14,76 & 15,03 & 13,99 & 12,90 \\
\hline
\end{tabular}

${ }^{1}$ Médias seguidas de mesma letra nas colunas não diferem entre si pelo teste de Tukey $(\mathrm{p} \leq 0,05)$ (means followed by same letters in columns did not differ from each other by the Tukey test $(\mathrm{p} \leq 0,05)) ; *$ dias após plantio; **dias após transplantio. $(*$ days after planting; $* *$ days after transplanting).

ceira e massa seca de parte aérea. A aplicação de $\mathrm{PBZ}$ aos $14 \mathrm{DAP}$ proporcionou mudas menores e com menor produção de massa seca de parte aérea e raiz. $\mathrm{O}$ PBZ não influenciou a sobrevivência das mudas em tubetes, número de perfilhos e massa seca de raiz das mudas.

A maior concentração de PBZ (1.800 $\mathrm{mg} \mathrm{L}^{-1}$ ) resultou em mudas menos desenvolvidas e com menor massa seca de parte aérea por muda. A utilização do produto também não influenciou o número de perfilhos por planta, não devendo ser recomendado na produção de mudas de vetiver.

Os genótipos UFS-VET001 e UFSVET004 apresentaram maior perfilhamento que o genótipo UFS-VET003, independente da aplicação de PBZ. A ausência de PBZ favoreceu a produção de maior número de pendões florais e de plantas mais baixas. Considerando os dados obtidos, o PBZ não deve ser recomendado para produção comercial de raízes de vetiver por não proporcionar redução de parte aérea e aumento do rendimento de raiz e óleo essencial.

\section{AGRADECIMENTOS}

Os autores agradecem à empresa Raro's Agroindústria de Produtos Aromáticas S.A. pelo financiamento da pesquisa e ao CNPq pelas bolsas de produtividade do primeiro autor e de ITI-A do segundo autor. 
Tabela 3. Número de pendões florais por touceira e altura de planta de vetiver, aos 182 dias após plantio em campo, em função de aplicações com paclobutrazol (number of ears and plant height, at 182 days after planting in field, as a function of paclobutrazol applications). São Cristóvão, UFS, 2007.

\begin{tabular}{lcc}
\hline Paclobutrazol (1500 mg L $\left.^{-\mathbf{1}}\right)$ & $\begin{array}{c}\text { Número de } \\
\text { pendões florais }\end{array}$ & $\begin{array}{c}\text { Altura de } \\
\text { planta (cm) }\end{array}$ \\
\hline Controle & $2,51 \mathrm{a}^{1 /}$ & $166 \mathrm{a}$ \\
$1500 \mathrm{mg} \mathrm{L}^{-1} 15 \mathrm{dap}^{*}$ nos tubetes & $1,53 \mathrm{~b}$ & $145 \mathrm{~b}$ \\
$1500 \mathrm{mg} \mathrm{L}^{-1} 15$ dap nos tubetes e 30 dat $^{* *}$ & $1,33 \mathrm{~b}$ & $138 \mathrm{~b}$ \\
em campo & 34,39 & 8,30 \\
\hline $\mathrm{CV}(\%)$ &
\end{tabular}

I/ Médias seguidas de mesma letra nas colunas não diferem entre si pelo teste de Tukey $(\mathrm{p} \leq 0,05)$ (means followed by same letters in columns did not differ from each other by the Tukey test $(\mathrm{p} \leq 0,05))$; *dias após plantio; **dias após transplantio $(*$ days after planting; $* *$ days after transplanting)

\section{REFERÊNCIAS}

ADAMS RP; DAFFORN MR. 1999. DNA fingerprints (RAPDs) of the pantropical grass vetiver, Vetiveria zizanioides (L.) Nash (Graminea), reveal a single clone 'Sunshine' is widely utilized in erosion control. Assumption University Journal of Technology 2: 173 180.

ADAMS RP; HABTE M; PARK S; DAFFORN, MR. 2004. Preliminary comparison of vetiver root essential oils from cleansed (bacteria- and fungus-free) versus non-cleansed (normal) vetiver plants. Biochemical Systematics and Ecology 32: 1137-1144.

ADAMS RP; PANDEY RN; DAFFORN MR; JAMES SA. 2003. Vetiver DNA-Fingerprinted cultivars: effects of environment on growth, oil yields and composition. Journal of Essential Oil Research 15: 363-371.

ALENCAR RG; PRADO CC; OLIVEIRA LMG; FREITAS MRF; SILVA LNM; NOGUEIRA JCM; PAULA JR; BARA MTF. 2005. Estudo Farmacobotânico e Fitoquìmico da Raiz de Vetiveria zizanioides L. Nash (Vetiver). Revista Eletrônica de Farmácia 2: 1-4.

ALI H; ATTIYAH; HASSOUN Q. 1998. Response of different genotypes of corn (Zea mays L.) to some plant growth regulators. Dirasat Agricultural Sciences 25: 296-310.
ALMEIDA SA; SANTOS AB; ALMEIDA TCS; ARRIGONI-BLANK MF; BLANK AF. 2007. Influência de métodos de desinfestação e tipos de explantes no estabelecimento in vitro de acessos de vetiver [Chrysopogon zizanioides (L.) Roberty]. Revista Brasileira de Horticultura Ornamental 13: 536-539.

BARRETT JE. Mechanisms of action. In: TAYAMA HK; LARSON RA; HAMMER PA; ROLLS TJ. 1992. Tips on the use of chemical growth regulators on floriculture crops. Columbus: Ohio Florists' Association. p.12-18.

BEROVA M; ZLATEV Z. 2003. Physiological response of paclobutrazol-treated triticale plants to water stress. Biologia Plantarum 46: 133-136.

CASTRO LO; RAMOS ELD. 2002. Principais gramíneas produtoras de óleos essenciais: Cymbopogon citratus (DC) Stapf., capimcidró, Cymbopogon martinii (Rox.) J.F. Watson, palma-rosa, Cymbopogon nardus (L.) Rendle, citronela, Elyanurus candidus (Trin.) Hack, capim-limão, Vetiveria zizanioides (L.) Nash, vetiver. Porto Alegre: FEPAGRO. 31p. (Boletim FEPAGRO, 11).

DHALIWAL RK; MALIK CP; GOSAL SS; DHALIWAL LS. 1997a. Studies on hardening of micropropagated sugarcane (Saccharum officinarum L.) plantlets. I. Root and shoot parameters. Annals of Biology Ludhiana 13:
21-25.

DHALIWAL RK; MALIK CP; GOSAL SS; DHALIWAL LS. 1997b. Studies on hardening of micropropagated sugarcane (Saccharum officinarum L.) plantlets. II. Leaf parameters and biochemical estimations. Annals of Biology Ludhiana 13: 15-20.

KIM HJ; CHENG F; WANG X; CHUNG HY; JIN Z. 2005. Evaluation of antioxidant activity of vetiver (Vetiveria zizanioides L.) oil and identification of its antioxidant constituents. Journal Agricultural and Food Chemistry 53: 7691-7695.

LAVANIA UC. 2000. Primary and secondary centers of origin of vetiver and its dispersion. In: INTERNATIONAL VETIVER CONFERENCE, 2. Proceedings ... Thailand: TVN. p. 424-426.

MARTINEZ J; ROSAPTV; MENUT C; LEYDET A; BRAT P; PALLET D; MEIRELES MAA. 2004. Valorization of brazilian vetiver (Vetiveria zizanioides (L.) Nash ex Small) oil. Journal Agricultural and Food Chemistry 52: 6578-6584.

ÖZMEN AD; ÖZDEMIR F; TÜRKAN I. 2003. Effects of paclobutrazol on response of two barley cultivars to salt stress. Biologia Plantarum, 46: 263-268.

RESENDE GM; SOUZA RJ. 2002. Efeitos de doses de paclobutrazol na cultura do alho. Pesquisa Agropecuaria Brasileira, 37: 637641.

SOUZA VC; LORENZI H. 2005. Botânica sistemática: guia ilustrado para identificação das famílias de angiospermas da flora brasileira, baseado em APG II. Nova Odessa, São Paulo: Instituto Plantarum. 640p.

VELDKAMP JF. 1999. A revision of Chrysopogon Trin. including Vetiveria Bory (Poaceae) in Thailand and Malasia with notes on some other species from Africa and Australia. Austrobaileya 5: 503-533.

YIM KO; KWONYW; BAYER DE. 1997. Growth responses and allocation of assimilates of rice seedlings by paclobutrazol and gibberellin treatment. Journal of Plant Growth Regulation 16:35-41.

XIA HP. 2004. Effects of plant growth retardants on growth of vetiver grass. TVN News Online. Disponível em: <http://www.vetiver.com./ CHN-growretard.htm>. Acessado em 19 fev. 2006. 